\title{
REMOÇÃO DE SÓLIDOS EM SUSPENSÃO NA ÁGUA RESIDUÁRIA DA DESPOLPA DE FRUTOS DO CAFEEIRO EM FILTROS CONSTITUÍDOS POR PERGAMINHO DE GRÃOS DE CAFÉ SUBMETIDO A COMPRESSÕES
}

\section{ANTONIO T. DE MATOS ${ }^{1}$, MARCOS A. MAGALHÃES ${ }^{2}$, DANILO C. FUKUNAGA ${ }^{3}$}

RESUMO: A remoção de sólidos em suspensão é fundamental para que se possa aplicar a água residuária gerada na despolpa de frutos do cafeeiro (ARC) na fertirrigação de culturas agrícolas. Dentre as opções disponíveis para efetuar a remoção de SS da ARC, está o uso de filtros orgânicos. Este trabalho foi desenvolvido com o objetivo de avaliar a influência do grau de compressão na redução do volume e na eficiência do pergaminho, utilizado como material filtrante, na remoção de sólidos em suspensão (SS) na ARC. Numa primeira etapa, foram realizados ensaios nos quais corpos-de-prova de pergaminho triturado (retido entre as peneiras de 2,5 e $3 \mathrm{~mm}$ ) e não-triturado (na condição em que é produzido) foram submetidos a diferentes compressões para a redução do volume das colunas filtrantes em $5 ; 10 ; 15 ; 20 ; 25$ e $28 \%$. Numa segunda etapa, os corpos-de-prova foram utilizados como material filtrante da ARC para a avaliação da sua capacidade de remoção de SS presentes nessa água residuária. O pergaminho triturado ofereceu maior resistência à compressão e proporcionou, para as mesmas reduções volumétricas no material filtrante, maior eficiência na remoção de SS da ARC do que o pergaminho não-triturado. Reduções na faixa de $10 \%$ a $15 \%$ no volume do filtro constituído por pergaminho triturado foram suficientes para obter satisfatórias eficiências na remoção de SS da ARC, enquanto, para filtros constituídos de pergaminho não-triturado, as reduções de volume devem ser superiores a $25 \%$.

PALAVRAS-CHAVE: café, filtros orgânicos, pergaminho de grãos do café.

\section{REMOVAL OF SUSPENDED SOLIDS IN THE WASTEWATER OF THE COFFEE SHRUB CHERRY PULPING BY FILTERS CONSTITUTED BY PARCHMENT OF THE COFFEE BEANS SUBJECTED TO COMPRESSIONS}

\begin{abstract}
The removal of suspended solids (SS) is fundamental to apply the wastewater from the coffee shrub cherry pulping (ARC) on agricultural crops fertigation. Among the available options for the removal of SS from ARC is the use of organic filters. This study was carried out to evaluate the influence of the compression degree on either volume reduction or parchment efficiency, when used as medium filter for the removal of suspended solids (SS) in ARC. In a first stage, some assays were conducted in which the testing sample of either triturated parchment (retained between the sieves with 2.5 and $3.0 \mathrm{~mm}$ ) and non-triturated one (under the condition which it is produced) were submitted to different compressions to reducing the volume of the filtering columns down to $5 ; 10 ; 15 ; 20 ; 25$ and $28 \%$. At the second stage, test specimens were used as a filtering material of ARC in order to evaluate its capacity to remove SS found in this wastewater. The triturated parchment appeared to be more resistant to the compression, as well as provided higher efficiency in removing SS and ARC for the same volumetric reductions in the filtering material than the non-triturated parchment. Range reductions from 10 to $15 \%$ in the filter volume constituted by triturated parchment were enough to obtain satisfactory efficiencies in removing the SS from ARC, whereas for those filters constituted by non-triturated parchment the volume reductions should be above $25 \%$.
\end{abstract}

KEYWORDS: coffee, organic filters, coffee bean parchments.

\footnotetext{
${ }^{1}$ Engo Agrícola, Professor Adjunto, Departamento de Engenharia Agrícola, Universidade Federal de Viçosa, Viçosa - MG, Bolsista do CNPq, atmatos@ufv.br

${ }^{2}$ Eng $^{\mathrm{o}}$ Agrônomo, Doutorando do Departamento de Engenharia Agrícola, UFV, Viçosa - MG.

${ }^{3}$ Engo ${ }^{\circ}$ Agrícola e Ambiental, Mestrando do Departamento de Engenharia Agrícola, UFV, Viçosa - MG.

Recebido pelo Conselho Editorial em: 6-10-2004
}

Aprovado pelo Conselho Editorial em: 13-4-2006

Eng. Agríc., Jaboticabal, v.26, n.2, p.610-616, maio/ago. 2006 


\section{INTRODUÇÃO}

A atividade de lavagem e despolpa de frutos do cafeeiro, necessária para a redução do custo de secagem e para a melhoria da qualidade de bebida, é geradora de grandes volumes de resíduos sólidos e líquidos, ricos em material orgânico e inorgânico que, se dispostos sem tratamento no ambiente, podem causar grandes problemas ambientais, como degradação ou destruição da flora e da fauna, além de comprometer a qualidade da água e do solo.

No processamento de frutos de cafeeiro, utiliza-se água para a lavagem, para o descascamento/despolpamento e para a desmucilagem. No descascamento/despolpa e desmucilagem, geram-se em torno de 3 a $5 \mathrm{~L}$ de água residuária (ARC) para cada litro de frutos processados (MATOS, 2003). Os elevados valores de Demanda Bioquímica de Oxigênio (DBO) e Demanda Química de Oxigênio (DQO) encontrados na água residuária desse processo são indicativos de que essas águas apresentam elevada carga orgânica e, por isso, podem trazer muitos problemas para corpos hídricos receptores se forem lançadas sem tratamento prévio.

Segundo a legislação ambiental vigente (CONAMA, 2005), as águas residuárias geradas no processo devem receber tratamento prévio antes de serem lançadas em corpo d'água receptor ou podem ser dispostas de forma ambientalmente adequada no solo, como disposição final. $\mathrm{O}$ aproveitamento agrícola da água residuária produzida para fertirrigação de culturas agrícolas tem sido considerado ambiental e economicamente adequado, tendo em vista que utiliza o valor fertilizante do resíduo com o objetivo de substituição de parte da adubação das lavouras. Entretanto, para possibilitar o aproveitamento dessas águas residuárias na fertirrigação de culturas agrícolas ou como forma de atenuar a carga orgânica, para facilitar e baratear o tratamento biológico posterior, é recomendada a filtragem do efluente do tratamento preliminar da ARC.

A filtração de suspensões é um processo físico de separação e, como tal, deve ser feito com a utilização de meio filtrante poroso, normalmente a areia, que vai tendo, aos poucos, seus poros obstruídos pelo material sólido contido na água residuária em tratamento. Por ser a ARC muito rica em sólidos em suspensão, o uso de filtros convencionais de areia não é recomendável, dada a sua rápida colmatação superficial e ao impedimento ao fluxo normal da água residuária (BRANDÃO et al., 2000). Segundo esses autores, a utilização de materiais alternativos à areia, que sejam subprodutos de atividades agropecuárias ou industriais, é interessante opção para uso no tratamento de águas residuárias ricas em material orgânico, como é o caso da ARC. Esse interesse está associado ao fato de que muitos resíduos sólidos gerados no processo produtivo ou no beneficiamento de produtos agrícolas podem ter destinação mais nobre na propriedade agrícola, minimizando-se os problemas da sua disposição no ambiente. Como opções de resíduos sólidos passíveis de utilização como material filtrante, podem ser citados o bagaço de cana-de-açúcar triturado, o sabugo de milho triturado, a serragem de madeira e o próprio pergaminho de grãos do café.

Lo MONACO (2001), avaliando a influência da granulometria do material na eficiência de remoção de poluentes e na taxa de filtração obtida, recomendou o uso de granulometrias entre 2 e $3 \mathrm{~mm}$, por serem as que proporcionaram mais eficiente filtração sem, contudo, aumentar em demasia a perda de carga no sistema.

Lo MONACO et al. (2002), ao utilizarem filtros orgânicos no tratamento da ARC, obtiveram remoções de sólidos totais de até $65 \%$ quando se utilizou de filtro constituído por serragem de madeira; no caso de filtro de bagaço de cana-de-açúcar, a remoção foi menor, alcançando $40 \%$. Em ambos os filtros, a remoção foi de $100 \%$ dos sólidos sedimentáveis, 75 a $85 \%$ do nitrogênio total e $50 \%$ do fósforo total. Os mesmos autores reportaram remoções acima de 60\% da DBO dessas águas residuárias, utilizando-se de filtros de serragem de madeira. MAGALHÃES et al. (2005) obtiveram remoções de sólidos em suspensão em águas residuárias da suinocultura da ordem de 90 a 99\%, utilizando filtros de serragem de madeira, e de 81 a $96 \%$ quando foram utilizados filtros de bagaço de cana-de-açúcar. De acordo com esses autores, para que não haja diminuição na eficiência de remoção de sólidos em suspensão e decréscimo muito acentuado na velocidade de 
filtração da água residuária, a compressão dos materiais filtrantes, tais como o bagaço de cana-deaçúcar e a serragem de madeira, no acondicionamento do material nos filtros, deve ser tal que promova redução de 5 a 10\% no volume da serragem de madeira e de 10 a $15 \%$ no caso do bagaço de cana-de-açúcar.

O fruto do cafeeiro é formado pelo grão (endosperma + embrião), que é envolvido pelo pergaminho ou endocarpo, pela polpa ou mesocarpo e, finalmente, pela casca ou epicarpo. $\mathrm{O}$ pergaminho do fruto do cafeeiro é a parte anatômica que envolve o grão e representa cerca de $12 \%$, em termos de matéria seca, do grão de café (MATOS \& Lo MONACO, 2003). Na condição natural, o pergaminho gerado no beneficiamento do grão apresenta elevada relação carbono/nitrogênio $(\mathrm{C} / \mathrm{N})$ e, portanto, taxa de degradação lenta. Entretanto, ao ser utilizado como material filtrante, terá a sua composição química alterada pelos nutrientes diluídos na ARC, o que deverá facilitar o seu tratamento pelo processo de compostagem, após ter sido descartado do filtro. Os sólidos retidos pelo filtro aumentarão a concentração de nutrientes no pergaminho e funcionarão como catalisadores do processo de compostagem, aspecto desejável para a aceleração da atividade microbiológica e que proporcionará a produção de adubos orgânicos de valor fertilizante mais elevado (MAGALHÃES et al., 2005).

Não foram encontrados na literatura estudos referentes ao uso do pergaminho dos grãos de café na filtragem de águas residuárias, razão pela qual foi conduzido o presente trabalho, no qual teve-se o objetivo de avaliar a influência do grau de compressão do pergaminho de grãos de café, na condição triturado e não-triturado, na eficiência de remoção de sólidos em suspensão em águas residuárias da despolpa de frutos do cafeeiro (ARC).

\section{MATERIAL E MÉTODOS}

Para a condução dos ensaios, foi utilizado, como material filtrante da ARC, o pergaminho de grãos de café, tal como é descartado no beneficiamento dos grãos, ou seja, não-triturado, e o mesmo material triturado em desintegrador/picador/moedor (DPM), $\mathrm{n}^{\mathrm{o}}$ 01, equipamento constituído de quatro conjuntos de três martelos (total de 12 martelos), peneira com malha de $10 \mathrm{~mm}$ e motor de $3,7 \mathrm{~kW}(5 \mathrm{cv})$. O material triturado foi posteriormente peneirado, de forma a obter a faixa granulométrica de 2,5 - 3,0 mm, conforme recomendado por Lo MONACO (2001).

Numa primeira etapa, foram conduzidos ensaios de compactação do material no Laboratório de Avaliação de Resistência de Materiais, do Departamento de Engenharia Civil da UFV, utilizando-se da prensa CBR para deformação dos corpos-de-prova, cujas dimensões eram de $15,2 \mathrm{~cm}$ de diâmetro e $17,9 \mathrm{~cm}$ de altura.

O pergaminho foi submetido a taxas de compressão que proporcionaram reduções de $5 ; 10$; 15; 20; 25 e $28 \%$ no volume ocupado pelo material, faixa em que se obtêm maiores alterações no volume com a compressão do material.

Numa segunda etapa, foi executado o ensaio de filtração, aplicando-se a ARC coletada na Unidade de Processamento de Frutos do Cafeeiro da UFV, sobre a superfície do material contido no recipiente do corpo-de-prova, para escoamento saturado da água residuária, no sentido verticaldescendente, mantendo-se, permanentemente, uma lâmina de $2 \mathrm{~cm}$ da ARC sobre a coluna filtrante.

Para a quantificação da concentração de sólidos em suspensão, no afluente e no efluente dos corpos-de-prova, as amostras foram encaminhadas para o Laboratório de Qualidade da Água do Departamento de Engenharia Agrícola da UFV, seguindo-se a metodologia descrita no Standard Methods for the Examination of Water and Wastewater (APHA, 1995) para a realização da análise.

Os dados obtidos no ensaio de compressão foram utilizados para a confecção da curva compressão x deformação volumétrica. Com os dados de concentração de sólidos em suspensão no afluente e efluente, calculou-se a eficiência de remoção dos filtros submetidos às compressões, plotando-se, posteriormente, a curva e obtendo-se as equações de eficiência do filtro na remoção de 
sólidos em suspensão em função da redução proporcionada no volume da camada de material filtrante.

A análise quantitativa dos dados foi constituída por ajuste de equações, por regressão linear e não-linear, sendo escolhidos os modelos dentre os que apresentaram comportamento físico coerente com o do fenômeno estudado, que apresentassem maiores coeficientes de determinação, além de significância, obtida com o emprego do teste " $t$ ", a $0,5 \%$ de probabilidade, para os coeficientes ajustados.

\section{RESULTADOS E DISCUSSÃO}

Os resultados dos ensaios de deformação do pergaminho de grãos de café, triturado e nãotriturado, estão apresentados na Figura 1. Avaliando-se o comportamento das curvas, verifica-se que, para a mesma deformação (redução de volume), o pergaminho triturado requer maior compressão, sendo essas diferenças de comportamento mais evidentes entre as reduções de 10 e $20 \%$ no volume do corpo-de-prova. Acredita-se que, nessa faixa de compressão, ocorra a deformação por amassamento do material que se encontrava formando grandes películas de formato côncavo-convexo, presentes em grande quantidade no pergaminho não-triturado.

Comparando-se os esforços executados no pergaminho triturado e no não-triturado com os necessários para que se obtivessem semelhantes deformações em serragem de madeira e bagaço de cana-de-açúcar de 2,5-3,0 mm, apresentados por MAGALHÃES et al. (2005), verificou-se que o pergaminho apresentou compressibilidade semelhante à do bagaço de cana-de-açúcar triturado, para reduções de até $15 \%$ no volume de material. A serragem de madeira, na mesma granulometria do bagaço de cana-de-açúcar, ofereceu, entretanto, muito maior resistência à deformação já a partir de reduções de volume de $10 \%$, tendo sido necessária pressão de $1.262 \mathrm{kPa}\left(12,86 \mathrm{kgf} \mathrm{cm}^{-2}\right)$ para que se promovesse redução de $15 \%$ no volume do corpo-de-prova.

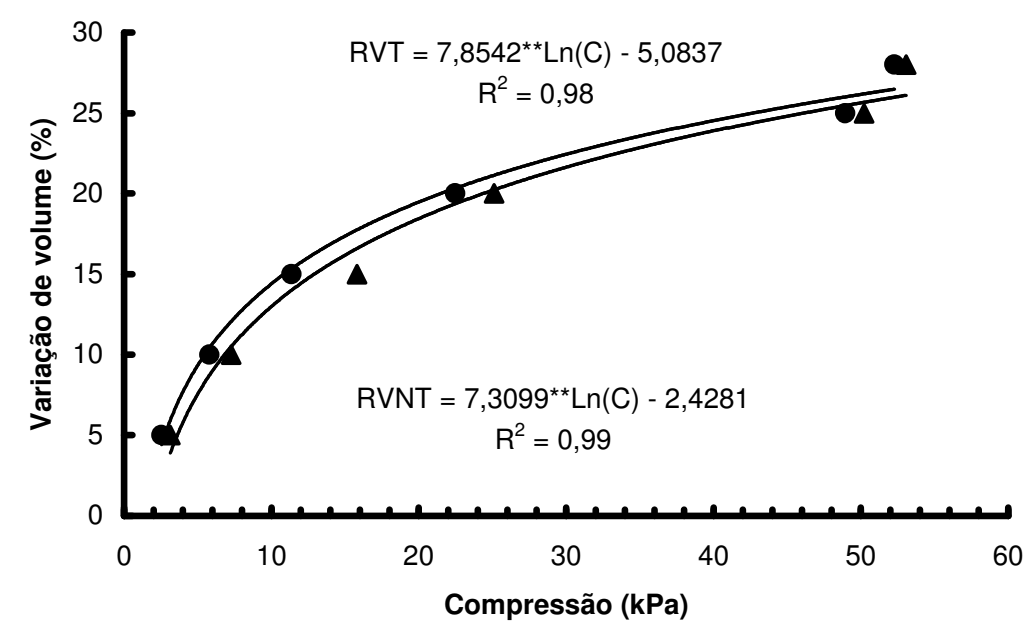

$\Delta$ Pergaminho triturado • Pergaminho não triturado

FIGURA 1. Redução de volume dos corpos-de-prova constituídos por pergaminho triturado (RVPT) e não-triturado (RVNT) de grãos de café, em função da compressão aplicada. ** significativo a $0,1 \%$ de significância.

Nas Tabelas 1 e 2, estão apresentados os valores das concentrações de sólidos em suspensão no afluente e efluente dos corpos-de-prova e os valores de eficiência de remoção obtidos. Pode-se verificar que, tanto para o pergaminho triturado como para o não-triturado, à medida que foi aumentada a pressão sobre o material contido no corpo-de-prova, houve redução na concentração de sólidos em suspensão no efluente dos filtros. Comparando-se as reduções de volume dos corposde-prova, verifica-se que maiores remoções de SS da ARC, especialmente sob as mais baixas 
compressões, foram obtidas quando o pergaminho foi triturado. À medida que ocorre maior compressão do volume do material, a tendência foi de diminuição nas diferenças, estimando-se que possa ocorrer igualdade na eficiência de remoção de SS com reduções de volume superiores a 32\% no volume dos corpos-de-prova constituídos por ambos os materiais. Entretanto, para que essa condição seja obtida, é necessário exercer compressão de $112 \mathrm{kPa}$ nos corpos-de-prova, valor muito alto para ser obtido de outra forma a não ser em prensas.

Pode-se verificar, também, que a compressão do pergaminho não-triturado é muito mais importante para que se possa obter adequadas remoções de sólidos em suspensão do que para o pergaminho triturado que, mesmo sob baixas compressões, proporcionou remoções relativamente altas (acima de 33\%) de sólidos em suspensão. Para que fossem obtidas remoções equivalentes às obtidas com $10 \%$ de redução do volume do pergaminho triturado, tornou-se necessária a redução de $26,5 \%$ no volume do corpo-de-prova de pergaminho não-triturado. Essa redução de volume pode ser obtida caso o material seja submetido à pressão superior a $50 \mathrm{kPa}$, valor acima do que pode ser obtido simplesmente por pisoteio de um homem, que deve estar entre 12,3 e 16,4 kPa (entre 0,125 e 0,167 kgf cm${ }^{-2}$ ) (BRANDÃO et al., 2000; MAGALHÃES et al., 2005).

TABELA 1. Concentração de sólidos em suspensão (SS) no afluente e efluente dos filtros com meios constituídos por pergaminho triturado, submetidos a compressões do material.

\begin{tabular}{lcccc}
\hline Suspensão & $\begin{array}{c}\text { Redução do Volume } \\
(\%)\end{array}$ & $\begin{array}{c}\text { Compressão } \\
(\mathrm{kPa})\end{array}$ & $\begin{array}{c}\text { Concentração de SS } \\
\left(\mathrm{mg} \mathrm{L}^{-1}\right)\end{array}$ & $\begin{array}{c}\text { Eficiência de } \\
\text { Remoção de SS (\%) }\end{array}$ \\
\hline Afluente & - & & 3.010 & - \\
\hline \multirow{4}{*}{ Efluente } & 10 & 3,14 & 2.000 & 33,6 \\
& 15 & 7,26 & 1.790 & 40,6 \\
& 20 & 15,79 & 1.640 & 45,5 \\
& 25 & 25,11 & 1.470 & 51,2 \\
\hline
\end{tabular}

TABELA 2. Concentração de sólidos em suspensão (SS) no afluente e efluente dos corpos-deprova constituídos por pergaminho não-triturado, submetidos a compressões do material.

\begin{tabular}{lcccc}
\hline Suspensão & $\begin{array}{c}\text { Redução do Volume } \\
(\%)\end{array}$ & $\begin{array}{c}\text { Compressão } \\
(\mathrm{kPa})\end{array}$ & $\begin{array}{c}\text { Concentração de SS } \\
\left(\mathrm{mg} \mathrm{L}^{-1}\right)\end{array}$ & $\begin{array}{c}\text { Eficiência de } \\
\text { Remoção de SS (\%) }\end{array}$ \\
\hline Afluente & - & & 3.010 & - \\
\hline \multirow{4}{*}{ Efluente } & 10 & 5,79 & 2.960 & 1,7 \\
& 15 & 11,40 & 2.810 & 6,7 \\
& 20 & 22,46 & 2.630 & 12,7 \\
& 25 & 48,95 & 2.030 & 21,5 \\
& 28 & 52,29 & 1.730 & 42,5 \\
\hline
\end{tabular}

Na Figura 2, estão apresentadas as curvas e as equações ajustadas para eficiência de remoção de sólidos em suspensão nos corpos-de-prova em função da redução proporcionada no volume de material filtrante.

Houve ajuste de equações exponenciais aos dados de eficiência na remoção de SS em função da redução no volume de filtro de pergaminho triturado e de pergaminho não-triturado. Pelos coeficientes de determinação obtidos, verifica-se que acima de 98,5\% da variação na remoção de SS foi explicada pela variação na redução do volume do corpo-de-prova.

As eficiências obtidas na remoção de sólidos em suspensão na ARC, obtidas no pergaminho triturado, podem ser consideradas altas, visto que o corpo-de-prova tinha menos de $17,9 \mathrm{~cm}$ de altura (com a compressão do material, houve redução ainda maior da altura de material filtrante) e 
que, segundo MATOS \& Lo MONACO (2003), a altura recomendada para filtros orgânicos é de $1,30 \mathrm{~m}$.

Os resultados indicaram que reduções de volume do material filtrante maiores que $20 \%$ proporcionam grandes aumentos na eficiência de remoção de sólidos em suspensão na ARC e, corroborando o que já foi anteriormente discutido, que a compressão do material é fundamental para que se possam obter aumentos na eficiência dos filtros. Possivelmente, a não-compactação do pergaminho não-triturado deva ser compensada pelo aumento da altura da coluna filtrante.

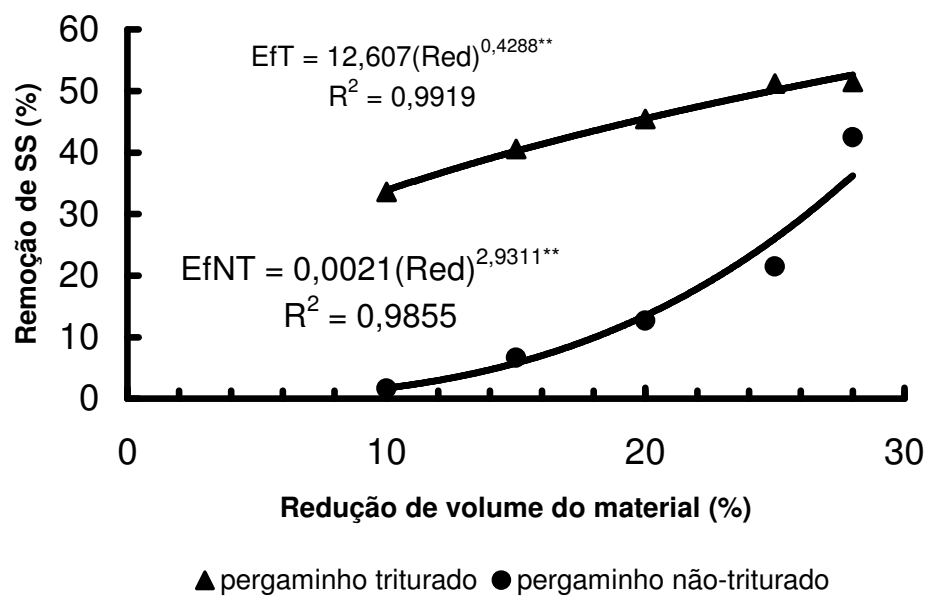

FIGURA 2. Eficiência na remoção de sólidos em suspensão na ARC em função da redução de volume proporcionada aos corpos-de-prova constituídos por pergaminho triturado (EfT) e não- triturado (EfNT). ** significativo a $0,1 \%$ de significância.

Considerando-se que a compactação proporcionada pelo pisoteio do material filtrante por um homem (pressão de 16,4 kPa) pode-se estimar, utilizando-se das equações apresentadas na Figura 1, redução de volume de $17,0 \%$ e $18,1 \%$ para pergaminho triturado e não-triturado, respectivamente, esses valores de redução de volume proporcionariam eficiências de remoção de sólidos em suspensão da ordem de $7 \%$ e $43 \%$, respectivamente, em filtros de pergaminho nãotriturado e de pergaminho triturado, de mesmas alturas dos corpos-de-prova utilizados neste estudo.

\section{CONCLUSÕES}

Para a obtenção de mesma redução volumétrica, o pergaminho triturado requer maior compressão do que o pergaminho não-triturado.

O aumento da compressão do material proporciona a obtenção de material filtrante, tanto para o pergaminho não-triturado como para o pergaminho triturado, de maior eficiência na remoção de sólidos em suspensão na água residuária do descascamento/despolpa dos frutos do cafeeiro (ARC).

Compressões que proporcionem reduções de volume na faixa de $10 \%$ a $15 \%$ no pergaminho triturado são suficientes para serem obtidas satisfatórias remoções de sólidos em suspensão na ARC.

Caso não se disponha de equipamento que possa triturar o pergaminho, recomenda-se efetuar compressões que proporcionem reduções de, no mínimo, $25 \%$ no pergaminho não-triturado, para a obtenção de maiores eficiências na remoção de sólidos em suspensão no tratamento da ARC.

O pisoteio proporcionado por um homem é suficiente para a compressão do pergaminho triturado a ser utilizado como material filtrante para a $\mathrm{ARC}$, porém não o é para o pergaminho nãotriturado. 


\section{REFERÊNCIAS}

AMERICAN PUBLIC HEALTH ASSOCIATION - APHA. Standard methods for the examination of water and wastewater. 19a. ed. New York: APHA/WWA/WPCR, 1995. "não paginado"

BRANDÃO, V.S.; MATOS, A.T.; MARTINEZ, M.A.; FONTES, M.P.F. Tratamento de águas residuárias de suinocultura utilizando-se filtros orgânicos. Revista Brasileira de Engenharia Agrícola e Ambiental, Campina Grande, v.4, n.3, p.327-33, 2000.

CONAMA. Conselho Nacional de Meio Ambiente. Resolução 357/2005. Disponível em: <http://www.siam.gov.mg.br:0/sla/dowload.pdf?idNormas=2747>. Acesso em: 02 abr 2006

Lo MONACO, P.A. Influência da granulometria do material orgânico filtrante na eficiência de tratamento de águas residuárias. 2001. 115 f. Dissertação (Mestrado em Recursos Hídricos e Ambientais) - Universidade Federal de Viçosa, Viçosa, 2001.

Lo MONACO, P.A.; MATOS, A.T.; MARTINEZ, M.A.; JORDÃO, C.P. Eficiência de materiais orgânicos filtrantes no tratamento de águas residuárias da lavagem e despolpa dos frutos do cafeeiro. Engenharia na Agricultura, Viçosa - MG, v.10, n.1-4, p.40-7, jan./dez. 2002.

MAGALHÃES, M.A.; MATOS, A.T.; AZEVEDO, R.F.; DENICULI, W. Influência da compressão no desempenho de filtros orgânicos para tratamento de águas residuárias da suinocultura. Engenharia na Agricultura, Viçosa - MG, v.13, n.1, p.26-32, 2005.

MATOS, A.T. Tratamento e destinação final dos resíduos gerados no beneficiamento do fruto do cafeeiro. In: ZAMBOLIM, L. Produção integrada de café. Viçosa: UFV/DFP, 2003. p.647-708.

MATOS, A.T.; Lo MONACO, P.A. Tratamento e aproveitamento agrícola de resíduos sólidos e líquidos da lavagem e despolpa de frutos do cafeeiro. Viçosa: UFV, 2003. 68 p. (Engenharia na Agricultura, Boletim Técnico, 7). 